\title{
Evaluation of the Implementation of the WHO's 2010 Guide on Prevention of Mother To-Child Transmission (PMTCT) of HIV/Aids: Case of Two Hospitals in Yaoundé
}

\author{
P. M. Tebeu1, E. Ngo Um Meka2 ${ }^{2}$, E. Bechem³ ${ }^{3}$ C. Ndomo ${ }^{4}$, F. Essiben ${ }^{4,5}$, R. E. Mbu ${ }^{4,5}$ \\ ${ }^{1}$ Yaoundé University Teaching Hospital, Yaoundé, Cameroon \\ ${ }^{2}$ Yaoundé Gynaeco-Obstetric and Paediatric Hospital, Yaoundé, Cameroon \\ ${ }^{3}$ Bamenda Regional Hospital, Bamenda, Cameroon \\ ${ }^{4}$ Faculty of Medicine and Biomedical Sciences, University of Yaoundé 1, Yaoundé, Cameroon \\ ${ }^{5}$ Yaoundé Central Hospital, Yaoundé, Cameroon \\ Email: *estherum@yahoo.fr
}

How to cite this paper: Tebeu, P.M., Meka, E.N.U., Bechem, E., Ndomo, C., Essiben, F. and Mbu, R.E. (2017) Evaluation of the Implementation of the WHO's 2010 Guide on Prevention of Mother To-Child Transmission (PMTCT) of HIV/Aids: Case of Two Hospitals in Yaoundé. Open Journal of Obstetrics and Gynecology, 7, 487493.

https://doi.org/10.4236/ojog.2017.75050

Received: November 29, 2016

Accepted: May 13, 2017

Published: May 16, 2017

Copyright @ 2017 by authors and Scientific Research Publishing Inc. This work is licensed under the Creative Commons Attribution International License (CC BY 4.0).

http://creativecommons.org/licenses/by/4.0/

\begin{abstract}
Introduction: The prevalence of HIV infection amongst pregnant women in Cameroon is $5.6 \%$. Mother-to-child transmission is a major expansion factor. In 2010, Cameroon adopted new strategies pegged to WHO guidelines. Objectives: The objective of this study was to evaluate the implementation of the new guidelines of prevention of mother to-child transmission (PMTCT) of HIV in the Yaoundé Central Hospital and the Yaoundé Teaching Hospital. Methodology: It was a cross sectional descriptive and prospective study over a period of 6 months in Yaoundé. It included all HIV-positive women, doing their antenatal care in the above cited hospitals, and having given their consent. The studied variables included socio demographic features, obstetrical history, the antenatal care, the initiation of anti retroviral (ARV) drugs, the ARV regimen, the number of years on ARV drugs, the mode of delivery and the mother and child outcome. The data was collected using a pre-tested questionnaire. They were obtained by interview of the seropositive pregnant women. Data were analysed using Epi info 3.5.3. Results: We performed 3104 antenatal consultations and 287 women were recruited in the study. The prevalence of HIV infection was $9.24 \%$. The mean age of women was 28.77 (SD: 5.13) years. The women were aged between 20 and 29 years in $51.20 \%$. Amongst the 156 women who knew their status before pregnancy, 109 (70.50\%) had their first ANC in the first trimester. All were managed according to the $2010 \mathrm{WHO}$ recommendations on PMTCT of HIV. Amongst the women unaware of their status, $25.20 \%$ had their booking ANC in the first
\end{abstract}


trimester, 25.14\% started ARVs at 14 weeks, 69.46\% at 28 weeks. We had 125 live births, $84.8 \%$ by vaginal route, neonatal prophylaxis in all babies was effective. Conclusion: PMTCT of HIV is available and guidelines are well applied in Yaoundé. Late treatment initiation still remains a problem to optimize care.

\section{Keywords}

HIV, ANC, Prevention of Mother to Child Transmission (PMTCT), ARV

\section{Introduction}

The acquired immune deficiency syndrome (AIDS) is a major public health problem worldwide and Africa is the most affected continent. According to UNAIDS in 2014, 36.9 million persons where living with the Human Immunedeficiency Virus (HIV) in the world and 24.7 million in Sub Sahara Africa. 70\% of persons living with HIV were in Sub-Sahara Africa [1].

The mother-to-child transmission of HIV (MTCT HIV) is one of the major causes of the progression of this affection in the paediatric population with about 430,000 new infections every year [1]. In the absence of preventive measures between $15 \%-45 \%$ of infants will be infected [2]. In the year 2000 Cameroon elaborated the first national strategic plan for the prevention of mother-to-child transmission of HIV and endorsed the World Health Organisation's guide in PMTCT of HIV in 2010. This guide included systematic antiretroviral (ARV) drugs to HIV infected pregnant women, ARV to the newborn, formula feeding to the newborn, vulvo-vagina cleaning with chlorhexidine during vaginal examinations, reduced frequency of vaginal examinations, non-artificial rupture of membranes, abstaining from milk-back of cord blood to the newborn, no systematic aspiration of airways of newborn and systematic washing of newborns in warm chlorhexidine water.

With the endorsement of this 2010 guide, several trainings were carried out on health care providers for its implementation. It was in an attempt to assess the effective implementation of this guide in some hospitals in Yaoundé.

The aim of the study was to describe the socio-demographic and obstetrical profile of pregnant women on ARV drugs, determine the prevalence of HIV in pregnant women, assess the availability, accessibility and application of PMTCT measures during antenatal consultations and delivery; and the different treatment regimens used.

\section{Methods}

We carried out a cross sectional descriptive and prospective study from 1st November 2012 to 30th April 2013 (6 months) in the obstetric/gynaecological unit of the Yaoundé Teaching hospital and Yaoundé Central Maternity.

The study population was made up of HIV seropositive pregnant women at- 
tending antenatal consultations in the place of study during the study period and who gave a written consent.

At the antenatal consultations, variables were socio-demographic characteristics, the different therapeutic combinations applied to both mothers and children, initiation and regimen of ARV.

In the labour room, we observed the various preventive gestures, in this particular case the use of the partogram, vaginal examination, duration of labor, measures of labour and outcome, delivery, artificial rupture of the membranes, vulvo-vaginal disinfection with chlorhexidine, the practice of episiotomies and instrumental delivery.

In post partum, our preoccupation was the putting under nevirapine of the newborns, their toilet, and the nutritional option chosen.

These variables were collected by interview using a pretested checklist.

Data collected was analysed with computer software Epi info 3.5.3 and Microsoft Excel 2007.

\section{Results}

During the study period 2104 clients were booked for antenatal consultations in the two hospitals, amongst whom 287 were HIV seropositive (9.24\%). The mean age of pregnant women was 28.77 (5.13) years. The age group $20-29$ years was mostly represented with $51.20 \%$ (Table 1 ).

Concerning parity, 244 women $(85.02 \%)$ had at least one previous pregnancy at term (Table 2).

Table 1. Sociodemographic characteristics of seropositive pregnant women.

\begin{tabular}{ccc}
\hline \multirow{2}{*}{ Characteristics (Age) } & \multicolumn{2}{c}{ Pregnant women with HIV } \\
\cline { 2 - 3 } & \multicolumn{2}{c}{$\mathrm{N}=287 \%$} \\
{$[17-19]$} & 12 & 4.20 \\
{$[20-29]$} & 147 & 51.20 \\
{$[30-39]$} & 122 & 42.50 \\
{$[40-43]$} & 6 & 2.10 \\
Total & 287 & 100
\end{tabular}

Table 2. Distribution of women considering their obstetric history.

\begin{tabular}{cccc}
\hline \multirow{2}{*}{ Obstetrical history } & \multicolumn{3}{c}{ Women with HIV } \\
\cline { 3 - 4 }$\leq 3$ & Gravidity & N \\
\hline$[4-6]$ & 157 & 54.70 \\
{$[7-9]$} & 115 & 40.10 \\
& Parity & 15 & 5.20 \\
0 & & 43 & 14.98 \\
1 & & 78 & 27.17 \\
{$[2-3]$} & 158 & 55.05 \\
{$[4-5]$} & 08 & 2.80 \\
\hline
\end{tabular}


Amongst the $287 \mathrm{HIV}$ positive pregnant women, 156 of them (54.36\%) knew their HIV status before pregnancy and 98 were on ARV drugs; 69 of whom were on ARV for more than 3 years $(70.48 \%)$ and 84 (85.72\%) for more than 5 years (Figure 1).

Of the 131 pregnant women who did not know their HIV status before pregnancy, only $33(25.2 \%)$ did their booking antenatal consultation in the first trimester of pregnancy (Figure 2). Only 29 of the 131 (22.14\%) women who were screened for HIV during pregnancy started ARV treatment from 14th week of gestation as recommended by the 2010 guidelines while 91 (69.46\%) started from 28th week of gestation (Figure 3). Pregnant women on ARV included those on bi-therapy regimen (60.60\%) and tri-therapy (39.40\%) (Table 3).

We had a total of 125 live births for which 14 (13.2\%) benefited from episiotomy. Vaginal delivery was conducted in 106 women $(84.8 \%)$ and caesarean in 19 (15.2\%). The four-hourly vaginal digital examination was respected in 99 parturients $(86.08 \%)$, while vulvo-vagina cleaning with chlorhexidine during vaginal examination was done in 114 women (99.13\%). Fourteen newborns $(11.2 \%)$ benefited from airways aspiration at birth (Table 4).

At birth, all the 125 newborns (100\%) received warm bath in chlorhexidine solution after birth and were given Nevirapine syrup. Formula feeding was the feeding method for 106 cases (84.8\%). All mothers received correct information on the duration of the Nevirapine regimen for their babies according to the method of feeding.

\section{Discussion}

On the availability of ARV drugs, our study outlined the effectiveness of the PMTCT of HIV. This finding is similar to that of Doherty $\mathrm{T}$ who reported in 2009 that $93 \%$ of health facilities in Cameroon had rapid tests and ARV drugs for PMTCT of HIV [3]. In the same year, Labhart in a study to assess the PMTCT

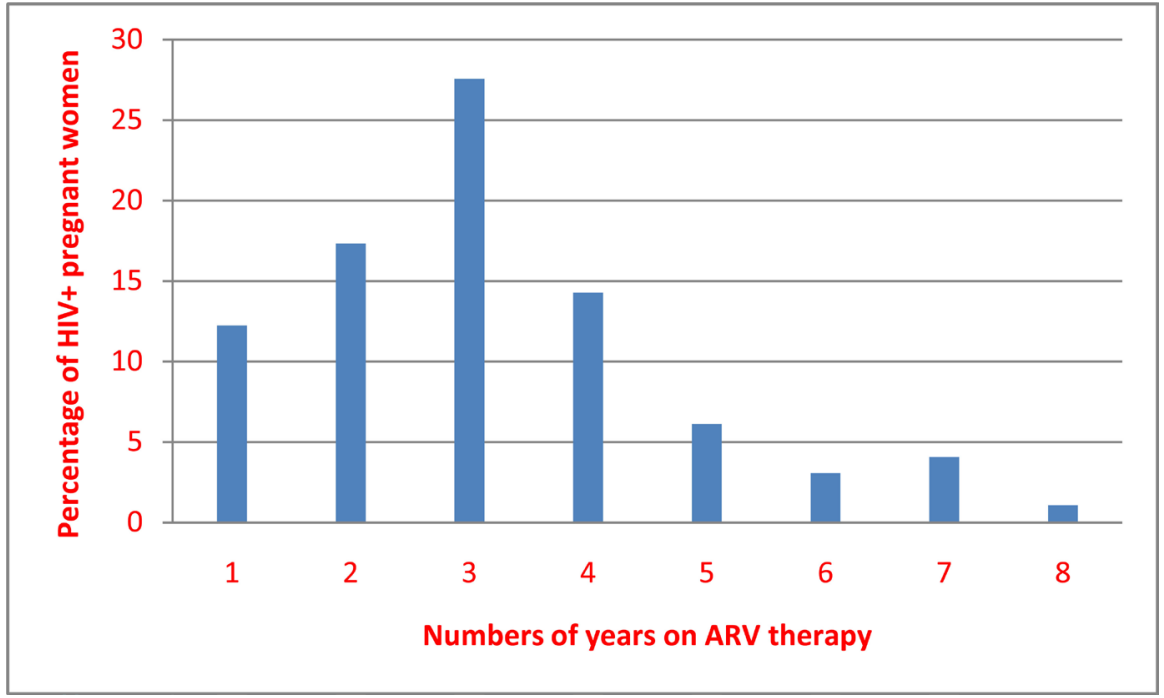

Figure 1. Distribution of the women according to the number of years under ARV before the current pregnancy. 


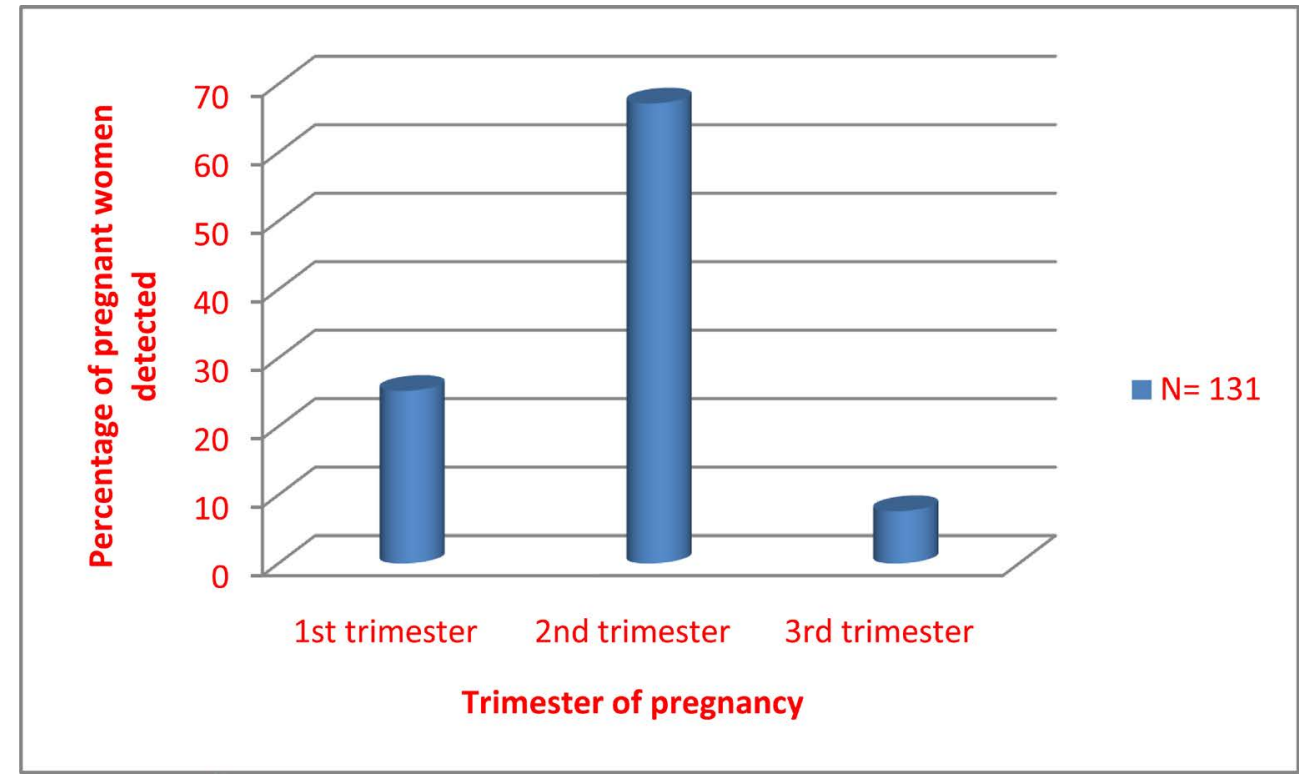

Figure 2. Distribution of the pregnant women detected in pregnancy according to the trimester.

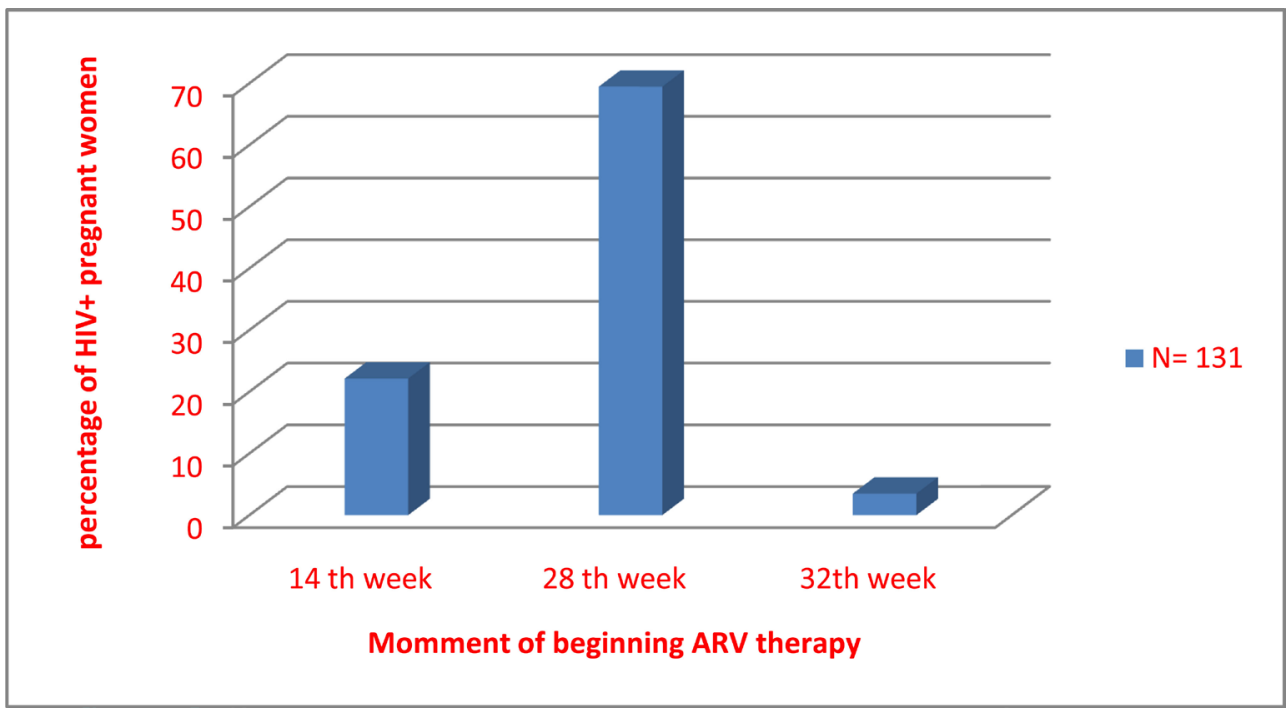

Figure 3. Distribution of the HIV-positive known pregnant women, according to the beginning of the ARV.

Table 3. Distribution of women according to the follow-up of the pregnancy.

\begin{tabular}{ccc}
\hline Variables & \multicolumn{2}{c}{ Women with HIV } \\
\cline { 2 - 3 } Period of diagnosis & $\mathrm{N}$ & $\%$ \\
Before pregnancy & 156 & 54.36 \\
During pregnancy & 131 & 45.64 \\
Therapeutic combination & & \\
Bitherapy & 174 & 60.60 \\
Tritherapy & 113 & 39.40 \\
\hline
\end{tabular}


Table 4. Distribution according to delivery.

\begin{tabular}{ccc}
\hline Period & N & $\%$ \\
\hline Delivery & 106 & 84.80 \\
Vaginal delivery & 19 & 15.20 \\
Caesarian section & & \\
Umbilical cord milking & 100 & 80 \\
Yes & 25 & 20 \\
No & & \\
Cleaning of the umbilical cord & 102 & 81.6 \\
Yes & 23 & 18.4 \\
No & & \\
Yes & 14 & 11.20 \\
No & 111 & 88.80 \\
\hline
\end{tabular}

services in rural Cameroon found out that rapid tests and material for sampling of venous blood were only in $63 \%$ of hospitals and only $23 \%$ had ARV drugs for PMTCT HIV [4]. This difference can be explained by the fact that our study was carried out in an urban setting and in only two referral hospitals.

On the treatment with ARV drugs, $62.82 \%$ of women screened positive before pregnancy were on ARV triple therapy. This finding is similar to that of others who reported $59.44 \%$ and $56.80 \%$ [5] [6]. This is the first line treatment for HIV-infected persons recommended by WHO.

All the 287 HIV seropositive pregnant women in our study were on ARV drugs. The problem we identified was between initiation of prophylaxis and treatment which was done late in pregnancy for newly tested pregnant women. For the pregnant women who started their booking antenatal consultation in the second trimester of pregnancy, only $22.14 \%$ were initiated to ARV drugs between 14 to 27 weeks of pregnancy. We also observed that only pregnant women screened HIV positive before pregnancy received ARV drugs from their booking antenatal consultation, according to WHO's recommendation the management of HIV positive pregnant women as soon as they arrive the health facility [7].

We also observed in our study that pregnant women who knew their HIV seropositive status before pregnancy started their booking antenatal consultation earlier. $70.21 \%$ of these women were booked for ANC in the first trimester against $25.20 \%$ of those who ignored their HIV serology before pregnancy explaining their late initiation of ARV drugs. Most pregnant women were on biotherapy $60.60 \%$ while $39.40 \%$ were on triple therapy.

Amongst the newly HIV screened pregnant women, $77.89 \%$ started ARV drugs from 28th week of pregnancy due to the late HIV screening which is a real problem in our setting.

On the mode of delivery, $84.8 \%$ of HIV positive pregnant women delivered 
vaginally. Similar findings were reported by Kantome in Cotonou (83.3\%) and Manefoue in Yaoundé (98.8\%) [6] [8]. These results are different from those of Mandelbrot L who reported $40 \%$ to $45 \%$ of vaginal birth in HIV seropositive pregnant women between 1999 and 2000 in the USA and 78\% in Europe [9] [10]. He reported that elective caesarean deliveries associated to ARV drugs reduced the rate of mother-to-child transmission of HIV to $2 \%$ in developed countries.

\section{Conclusion}

We can conclude that PMTCT of HIV services is very well presented in the hospitals where the study was carried out and that the WHO new directives were applied. Consequently HIV positive pregnant women screened before pregnancy had a better follow-up because they presented early in pregnancy for booking ANC.

\section{Limitations of the Study}

Our study was carried out in an urban area and in reference hospitals. The results obtained may include a bias if extrapolated to rural areas that have specific difficulties.

\section{References}

[1] Third Demographic Health Survey. Cameroon 2011.

[2] UNAIDS: 2014 Global Incidence of HIV. www.unaids.org

[3] Doherty, T., Chopra, M., Nsibande, D. and Mogoma, D. (2009) Improving the Coverage of the PMTCT Program through a Participatory Quality Improvement Intervention in South Africa. BMC Public Health, 9, 406. https://doi.org/10.1186/1471-2458-9-406

[4] Labhardt, N.D., Manga, E., Baki, J.R., Bischoff, A. and Stall, B. (2009) Early Assessment of the Implementation of a National Program for the Prevention of Mother to Child Transmission of HIV in Cameroon and the Effects of Staff Training: A Survey in 70 Rural Health Care Facilities. Tropical Medicine \& International Health, 14, 288-293. https://doi.org/10.1111/j.1365-3156.2009.02221.x

[5] Diallo, M. (2003) VIIème congrès de la SAGO, IIème congrès de la SOMAGO. Abstract.

[6] Mody, C. Suivi de la PEC des femmes enceintes séropositives au VIH sous traitement ARV dans le cadre de la PTME dans le service de gynécologie obstétrique au CHU.

[7] WHO (2015) Prevention of Mother-to-Child Transmission of HIV. www.who.int

[8] Kantome, G. (2003) Contribution à l'amélioration du suivi des enfants nés de mères infectés par le VIH dans le cadre de la PTME. Mémoire de santé publique. Cotonou IRSP.

[9] Manefoue, C. Etude épidémiologique de la transmission materno-fœetale du VIH chez les femmes enceintes au centre hospitalier les dominicains Saint-Martin de Porres Yaoundé. Mémoire VIH/SIDA.

[10] Mandelbrot, L. Syndrome d'immunodéficience acquise et grossesse EMC C5-039D40. 
Submit or recommend next manuscript to SCIRP and we will provide best service for you:

Accepting pre-submission inquiries through Email, Facebook, LinkedIn, Twitter, etc. A wide selection of journals (inclusive of 9 subjects, more than 200 journals)

Providing 24-hour high-quality service

User-friendly online submission system

Fair and swift peer-review system

Efficient typesetting and proofreading procedure

Display of the result of downloads and visits, as well as the number of cited articles Maximum dissemination of your research work

Submit your manuscript at: http://papersubmission.scirp.org/

Or contact ojog@scirp.org 